\title{
Laboreal
}

Volume $10 \mathrm{~N}^{\circ} 1$ | 2014

Análise ergonómica do trabalho e formação

\section{Preâmbulo e introdução do livro "Didática psicológica. Aplicação à didática da psicologia de Jean Piaget"}

Prólogo e introducción del libro "Didáctica psicológica. Aplicación a la didáctica de la psicología de Jean Piaget"

Avant-propos et introduction du livre "Didactique psychologique. Application à la didactique de la psychologie de Jean Piaget "

Prologue and introduction of the book "Psychological didactics. Application of the Jean Piaget psychology"

\section{Hans Aebli}

Tradutor. João Viana Jorge

\section{(2) OpenEdition}

\section{Journals}

Edição electrónica

URL: http://journals.openedition.org/laboreal/5428

DOI: 10.4000/laboreal.5428

ISSN: 1646-5237

Editora

Universidade do Porto

\section{Refêrencia eletrónica}

Hans Aebli, «Preâmbulo e introdução do livro "Didática psicológica. Aplicação à didática da psicologia de Jean Piaget" », Laboreal [Online], Volume $10 N^{0} 1$ | 2014, posto online no dia 01 julho 2014,

consultado o 23 setembro 2020. URL : http://journals.openedition.org/laboreal/5428 ; DOI : https:// doi.org/10.4000/laboreal.5428

\section{Este documento foi criado de forma automática no dia 23 setembro 2020.}

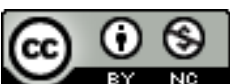

Laboreal está licenciado com uma Licença Creative Commons - Atribuição-NãoComercial 4.0 Internacional. 


\section{Preâmbulo e introdução do livro "Didática psicológica. Aplicação à didática da psicologia de Jean Piaget"}

Prólogo e introducción del libro "Didáctica psicológica. Aplicación a la didáctica de la psicología de Jean Piaget"

Avant-propos et introduction du livre "Didactique psychologique. Application à la didactique de la psychologie de Jean Piaget "

Prologue and introduction of the book "Psychological didactics. Application of the Jean Piaget psychology"

\section{Hans Aebli}

Tradução : João Viana Jorge

\section{REFERÊNCIA}

Artigo original : Aebli, H. (1951). Didactique psychologique. Application à la didactique de la psychologie de Jean Piaget. Neuchâtel : Delachaux \& Niestlé.

\section{NOTA DO EDITOR}

http://dx.doi.org/10.15667/laborealx0114ha 


\section{Preâmbulo[1]}

1 Os próprios títulos das obras de Jean Piaget põem em evidência a significação que a sua doutrina científica reveste para a didática. A génese do número na criança, 0 desenvolvimento das quantidades na criança, A geometria espontânea da criança, são todos títulos que deixam entrever um material rico em observações e reflexões que se prestam a uma aplicação imediata ao ensino - impressão que vem confirmar o estudo mais aprofundado desta grande obra psicológica.

2 A psicologia de Jean Piaget é genética. Não se limita a estudar as reações características do adulto, ou de um período isolado da infância, uma vez que analisa a própria formação das noções e operações no decurso do desenvolvimento da criança. Daí resulta não somente uma compreensão aprofundada dos estados finais do desenvolvimento mental, mas também um conhecimento preciso dos seus mecanismos de formação. Ora é evidente que estes últimos interessam ao didata ao mais alto nível. Porque este não aponta a outro alvo senão ao de provocar de maneira consciente e sistemática os processos de formação intelectual, que a psicologia genética, pelo seu lado, estuda na atividade espontânea da criança. E não poderia pôr-se em dúvida que o conhecimento exato destes processos é absolutamente necessário quando nós nos propomos provocá-los através de situações de aprendizagem e de atividades escolares apropriadas.

3 Em segundo lugar, a psicologia de Jean Piaget analisa, com particular sucesso, as funções mentais superiores, a saber: as noções, operações e representações cujo conjunto constitui o pensamento humano. Ora, neste caso, esta psicologia responde ainda a uma necessidade precisa, porque os problemas didáticos mais difíceis não dizem respeito à aquisição de hábitos, de automatismos ou de outros mecanismos primitivos, mas à formação de noções, de representações complexas e de operações constituindo sistemas de conjunto (tabuada da multiplicação, regras da gramática, etc.). Ora, é também bem evidente que só uma psicologia tal como a de Jean Piaget, que fornece uma análise precisa das operações mentais e dos seus grupos e agrupamentos, pode fornecer os conceitos necessários para a solução de semelhantes problemas didáticos : as doutrinas centradas nas funções elementares tais como a motricidade, a perceção ou a associação não esclarecem as reações psíquicas mais complexas.

É uma didática geral a que aqui apresentamos ao leitor: estuda as características fundamentais dos processos formativos e daí deduz os princípios metodológicos sobre os quais deve assentar o ensino de todas as áreas fundamentais. Ainda que fornecêssemos um grande número de exemplos concretos, retirados mais frequentemente do ensino primário, não se encontraria neste livro a didática completa de nenhuma área do ensino. Propusemo-nos, pelo contrário, definir as noções fundamentais e o quadro geral comuns a todas as didáticas específicas. Admitiríamos que esta metodologia teria cumprido a sua função, se se demonstrasse que pode servir para ordenar melhor o tão complexo domínio da didática, se as teses emitidas nas partes psicológica e didática incitassem outros investigadores a empreender novas experiências ou se os professores primários que os lessem adquirissem algumas ideias novas para o seu trabalho prático.

5 Tendo nós próprios ensinado no primário e no secundário, cremos saber o que o praticante espera de uma obra didática : além dos princípios pedagógicos gerais, são exemplos concretos mostrando exatamente como o autor entende proceder, e isto em 
situações escolares reais que frequentemente só oferecem possibilidades muito limitadas de realização, face aos postulados da nova escola. É por razões destas que empreendemos numerosas experiências didáticas destinadas a verificar como e com que sucesso as nossas propostas podem ser postas em prática nas condições escolares correntes [2]. Publicamos, além disso, na parte experimental desta obra os protocolos detalhados das lições que demos no quadro de uma dessas experiências. Pedimos desculpa se essas descrições parecem um pouco longas a um ou outro dos nossos leitores: elas não são reproduzidas apenas para permitir a outros investigadores repetir e verificar a nossa experiência, mas ainda e sobretudo para mostrar aos nossos colegas do ensino como concebemos a realização prática dos nossos princípios didáticos.

6 O próprio Piaget sugeriu-nos que escrevêssemos este trabalho ; as suas considerações e conselhos foram da maior utilidade ao longo de toda a sua realização. Além disso, permitiu-nos designar este livro como uma aplicação à didática da sua psicologia. Queira, portanto, Piaget aceitar a presente obra, não somente como uma nova confirmação do valor da sua doutrina psicológica, mas também como um sinal do nosso profundo reconhecimento pela confiança e pelo encorajamento que nunca cessou de nos testemunhar.

H. A.

\section{Introdução}

\section{A contribuição da psicologia para a solução de problemas didáticos}

O objetivo do presente trabalho é o de estudar algumas das possíveis aplicações, da psicologia de Jean Piaget, à didática.

Começaremos por colocar o problema e definir os seus termos. O que é de facto a didática? É uma ciência auxiliar da pedagogia na qual esta última delega, para as realizações de pormenor, as tarefas educativas mais gerais. Como levar o aluno a adquirir tal noção, tal operação ou tal técnica de trabalho ? São esses os problemas que o didata procura resolver fazendo apelo ao seu conhecimento psicológico das crianças e dos seus processos de aprendizagem.

11 Existe assim uma didática da aritmética, dos trabalhos manuais, do canto, etc. ; todavia limitaremos o presente estudo às aquisições intelectuais, referindo-nos ainda obviamente - aos outros aspetos da vida psíquica, na medida em que constituem condições ou consequências da formação intelectual.

12 A fim de aclarar a contribuição que a psicologia pode proporcionar à solução dos problemas didáticos, comecemos por nos interrogar como são geralmente determinadas as tarefas da didática. Em quase todos os programas escolares, tais tarefas são definidas em termos de noções a adquirir : noções de geografia, de física, de aritmética, etc. Eis as " matérias» que o aluno deve " aprender », que deve assimilar para as " conhecer ». Mas, que significa conhecer um objeto como " a alavanca » ou uma noção como "a fração ordinária » ? Será a capacidade de apresentar uma definição ? É evidente que não. Dir-se-á então que o aluno deve possuir uma representação da alavanca, imaginar o mecanismo do seu funcionamento? Talvez; mas ainda falta 
explicitar o que se entende exatamente quando se diz que a criança deve adquirir esta ou aquela representação. No domínio do pensamento matemático, o problema é o mesmo. Que significa possuir a noção de fração ordinária ? Quando é que pode afirmarse que ela foi adquirida pela criança ? o educador desprevenido acredita, por vezes, que a aquisição está concluída quando os alunos são capazes de resolver os problemas que impliquem as noções e as operações em questão. Ora, frequentemente o fracasso total da turma perante um problema colocado sob um formato pouco habitual evidencia que as crianças nem sequer assimilaram a noção e que usam simplesmente um " truque ».

o problema didático assim colocado é de ordem geral. Traduz o facto de que as “ matérias » (factos, noções, etc.), inicialmente de algum modo exteriores ao espírito da criança, devem tornar-se elementos do seu pensamento. Sem analisar ainda esse processo de aquisição, é preciso definir-lhe o resultado desejado, que se exprime dizendo que a criança " conhece o facto " ou que " adquiriu a noção ». É esse o primeiro problema importante que se coloca a qualquer didática. Incumbe, sem dúvida, à psicologia do pensamento responder-lhe com um máximo de autoridade.

14 Mas há mais. Qualquer didática deve definir, e define de facto, não somente como os alunos " conhecem » uma certa matéria mas também como a " aprendem ». Tomemos o exemplo de um pedagogo para quem a noção de fração é uma imagem mental, depositada, como que por impressão fotográfica, no espírito dos alunos. Com o objetivo de provocar esse processo, apresentará à turma imagens de círculos divididos em sectores que pendurará nas paredes da sala durante um período prolongado e que mandará copiar, colorir, etc. Este exemplo ilustra uma das soluções (aliás, falsa, como nos esforçaremos por mostrar a seguir) dadas a um segundo problema didático que apela para uma solução psicológica: a de determinar com precisão a natureza dos processos de aquisição pelos quais a criança assimila os factos e as noções.

15 À didática incumbe, além disso, o cuidado de estudar as condições mais favoráveis a esses processos de formação. Ainda aí enfrentamos um campo muito amplo de problemas psicológicos que levantam as questões da necessidade, do interesse, da atenção, da organização social da atividade escolar. 0 professor primário apoia-se no seu conhecimento psicológico da criança para ter em conta essas condições nos seus ensinamentos.

16 A didática científica atribui-se como tarefa deduzir do conhecimento psicológico dos processos de formação intelectual as medidas metodológicas mais aptas a provocá-los. Tal relação entre a didática e a psicologia não se estabelece senão raramente duma maneira consciente e direta. E, todavia, qualquer método de ensino é solidário com uma psicologia da criança e do seu pensamento, frequentemente não explicitada, é verdade, mas tacitamente pressuposta. A análise atenta de uma metodologia, e mesmo de simples práticas didáticas em uso nas escolas, revela bastante facilmente as conceções psicológicas subjacentes.

17 Estas considerações sugeriram-nos, para esta obra, o plano seguinte : começaremos por estudar a solução dada ao problema da formação das noções e operações pela didática do século XIX. Depois, tentaremos mostrar que esta metodologia é solidária com a psicologia e a filosofia “sensualista-empirista " em voga na mesma época. Numa segunda secção da parte histórica passaremos em revista algumas teorias reformadoras do século XX e os seus fundamentos psicológicos, nomeadamente diversos movimentos pedagógicos habitualmente agrupados sob a designação de teorias da "escola ativa ". Numa terceira parte consideraremos certos aspetos da psicologia de Jean Piaget que 
nos parece poderem servir de base a princípios metodológicos, cuja exposição constituirá o conteúdo dos capítulos seguintes. Finalmente, ilustraremos as nossas sugestões com a descrição de uma experiência didática que nós mesmo conduzimos nas escolas públicas do cantão de Zurique.

\section{NOTAS}

1. Nota do tradutor: Para uma apresentação mais ampla da obra de H. Aebli em espanhol o leitor pode consultar: "El pensamiento didáctico de Hans Aebli" de Ricardo Lucio. www.pedagogica.edu.co/storage/.../rce25_05ensa.pdf

2. Permita-se-nos agradecer aqui a E. Kuen e E. Keller de Kusnacht e a H. Seller e T. Frey de Zurique que colocaram à nossa disposição as suas turmas e que fizeram tudo quanto lhes foi possível para facilitar a realização das nossas experiências 